\title{
Diurnal habitat suitability for a Mediterranean steppeland bird, identified by Ecological Niche Factor Analysis
}

\author{
Stefano Triolo ${ }^{\mathrm{A}}$, Daniela Campobello ${ }^{\mathrm{A}, \mathrm{B}}$ and Maurizio Sarà ${ }^{\mathrm{A}}$ \\ A Department of Environmental Biology and Biodiversity, University of Palermo, Via Archirafi, \\ 18-123 Palermo, Italy. \\ ${ }^{B}$ Corresponding author. Email: danielacampobello@hotmail.com
}

\begin{abstract}
Context. The negative effects of agricultural intensification and policies, use of pesticides, fertilisers and mechanised harvesting on several populations of pseudo-steppe birds have increasingly required more detailed and effective habitat suitability models. Distribution models of farmland species are prone to incur recordings of false absence data. Ecological Niche Factor Analysis (ENFA) allows identification of environmental predictors of species distribution by using presence data only.

Aims. We quantified the diurnal habitat preferences and niche width of one steppe species, the stone curlew (Burhinus oedicnemus), with unfavourable conservations status in a Mediterranean area and reclassified a map with respect to habitat suitability classes according to the resulting distribution model.

Methods. Ecological Niche Factor Analysis was used with GIS cartography customised with habitat and anthropogenic variables recorded during field surveys carried out in four study plots ( $\sim 500 \mathrm{ha})$ and at different spatial scales.

Key results. The stone curlew selected areas with low vegetation cover, such as fields following artichoke harvesting and tillage, close to rural buildings and unpaved roads. In contrast, the stone curlew avoided areas with high vegetation cover and areas highly disturbed by human-induced fires. The occurrence of natural vegetation was neither preferred nor avoided. The most robust model was based on a large-scale analysis ( $200 \mathrm{~m}$ from the bird location points), according to which the optimal area for stone curlew distribution during its breeding season was restricted to $1 \%$ of the entire study area.

Conclusions. Two uncorrelated factors, 'marginality' and 'tolerance', described the stone curlew's niche in the area. The first index indicated selection for habitats that were marginal with respect to those available in the area, whereas the second indicated a species with a medium-wide environmental niche. In particular, the stone curlew occupied a much more restricted niche (low tolerance) in relation to individual variables. The use of customised databases at a large scale of analysis was found to more effectively reveal ecological requirements of this marginal and specialised species.

Implications. Our results allowed us to indicate practical land management actions for the stone curlew, such as prevention of human-induced fires and increase of pastoral activities. Our results indicated a potentially positive role of littledisturbed service roads along rural buildings in stone curlew distribution, which warrants further research. In addition, studies are needed to verify the presence of an ecological trap in artichoke fields, their preferred habitat. As we showed for the stone curlew, niche analyses conducted at a large scale using customised databases could greatly improve habitat suitability models of farmland species.
\end{abstract}

\section{Introduction}

Agricultural intensification has an undisputed role in the negative biodiversity trends recorded among pseudo-steppe avifauna since the mid-20th century (Pain et al. 1997; Donald et al. 2007; Sirami et al. 2008). Declines in populations of farmland specialists have been attributed to policy-driven agricultural changes (Donald et al. 2001, 2006). Since their first applications, agricultural policies have promoted the conversion of natural habitats and grassland to large-scale cultivated fields, on which pesticides, fertilisers and mechanised harvesters are used (Sanderson et al. 2005). The immediate consequence of these activities has been a drastic reduction in mixed farming, fallow land and habitat diversity (Herkert 1997; Wolff 2005). The effects on pseudo-steppe birds include the loss of foraging and nesting habitats (Arroyo et al. 2002; Burfield 2005; Sim et al. 2007), decreased prey availability (Benton et al. 2002), increased predation vulnerability (Bro et al. 2004), and breeding failure (Ghilain and Bélisle 2008). Numerous studies conducted in the past decades have found robust evidence that there is a causal link between the aforementioned effects and the population declines of some species, such as the grey partridge (Perdix perdix; Pépin et al. 2008), little bustard (Tetrax tetrax; Salamolard and Moreau 1999), and skylark (Alauda arvensis; Reif et al. 2008).

One of the most recent approaches to studying conservation policies has been the application of Ecological Niche Factor Analysis (ENFA), which allows the quantification of not only habitat preferences but also the breadth of species niches, used as the basis to develop maps indicating the most suitable habitat in the study areas and, therefore, the identification of real or 
potential species distributions (Hirzel et al. 2002; Braunisch et al. 2008). This multivariate tool has been extensively used to identify hotspots where increased environmental protection should be directed (Hirzel et al. 2004; Sattler et al. 2007; Gomes et al. 2009; Puddu et al. 2009) by detecting sensitive variables representing vital elements in the distribution of highly specialised species, such as stony corals (Tittensor et al. 2009), bats (Sattler et al. 2007), the Apennine brown bear (Ursus arctos marsicanus; Falcucci et al. 2009) and the lynx (Lynx lynx; Basille et al. 2008).

As it applies to farmland species, ENFA has provided important information for the conservation of reptile assemblages (Santos et al. 2006; Ribeiro et al. 2009), but there has been relatively little use of this tool to determine the niche breadth of farmland specialist birds. Moreover, the few studies on this topic have focussed on the effects of land abandonment as opposed to agricultural intensification (Acevedo et al. 2007; Sirami et al. 2008). Moreover, a question addressed by models of habitat preferences of farmland species is the identification of a proper resolution of spatial analysis (Wolff et al. 2002; Sim et al. 2007). Niche analyses conducted on different spatial scales might, in fact, greatly improve the availability of information necessary for implementing conservation practices by indicating the most appropriate spatial scale on which to operate. Thus, management actions would be based not only on the immediate spatial characteristics preferred by a species but also on the surrounding habitat within a range of distances depending on the species niche breadth (Wolff et al. 2002). Compared with other multivariate tools available (Guisan and Zimmermann 2000), ENFA requires presence-only data and therefore prevents evaluation errors due to the inclusion of false absences in the model (Hirzel et al. 2001). This requirement makes ENFA particularly suitable and innovative for developing distribution models applied to pseudo-steppe birds, several of which are prone to false absence recordings because they have cryptic plumage and exhibit elusive behaviour. However, to our knowledge, no maps of habitat suitability based on niche analyses for pseudo-steppe bird distribution have yet been produced.

Although niche analyses have become more popular with the increased availability of geosystem information databases, they are usually based on large-scale environmental data obtained from national or satellite maps (Sattler et al. 2007; Ribeiro et al. 2009; Tittensor et al. 2009). The use of such coarse-grained databases has often resulted in contrasting results when identifying ecological requirements, especially for species that select very specific habitat types (Haworth and Thompson 1990; Buchanan et al. 2003). In addition, MorenoRueda and Pizzarro (2009) pointed out that the use of large (national) scales may obscure a significant part of a species' distribution variance, hence diminishing the explanatory power of environmental variables.

In this study, we applied ENFA to a pseudo-steppe bird, the stone curlew (Burhinus oedicnemus), which has suffered a drastic population decline since the early 1990s (Tucker and Heath 1994; Onrubia and Andrès 2005) and is listed as having an unfavourable conservation status in Europe (SPEC 3, BirdLife International 2004). The stone curlew is a ground-nesting species living in scattered populations, which are especially concentrated in the Iberian Peninsula, France, Italy and the Balkan region (Cramp and Simmons 1983). Agricultural intensification has been identified as the main cause of the population decline of this species in the UK (Pain et al. 1997; Green et al. 2000), whose conservation status has been lowered from red to amber thanks to heavy conservation interventions (Gregory et al. 2002; Evans and Green 2007; Taylor et al. 2007). In Italy, the highest densities of the stone curlew are reported in the south (Brichetti and Fracasso 2004), with peak populations in Sicily (Ientile and Massa 2008) and, in particular, on the Gela Plain, where densities of 2.8 individuals per 100 ha occur (Mascara and Sarà 2007). Nevertheless, Italy also lists the stone curlew as an endangered species in its national Red List, which is most likely due to the effects of profound habitat modifications and intense agricultural practices (Bulgarini et al. 1998).

The main goal of this investigation was to produce a distribution map of the most suitable diurnal habitat for the stone curlew population living on the Gela Plain. By using an Ecological Niche Factor Analysis of habitat and anthropogenic variables as possible proxies of the stone curlew's distribution, we determined the environmental preferences of this species and quantified its niche breadth, which was used as the basis for a distribution map of its habitat suitability. We accomplished this goal by first developing our own environmental databases from field surveys, followed by comparing the reliability and predictive power of models operating at different spatial scales. We then discussed the implications for wildlife and land use management derived from such different scales of analysis in our perception of habitat suitability.

\section{Materials and methods}

\section{Study area}

The study was carried out on the Gela Plain $\left(37^{\circ} 07^{\prime} \mathrm{N} ; 14^{\circ} 20^{\prime} \mathrm{E}\right)$, which is one of the largest plains in Italy $\left(\sim 474 \mathrm{~km}^{2}\right)$. It is located in southern Sicily (Fig. 1), and the paucity of precipitation (350 mm per year; LIPU 2009) results in a typical pseudosteppe habitat characterised by slightly steep hills composed of calcareous, sand and clay soils (Goriup 1988; Raimondo 1998). Its territory today includes (EEA 2000; LIPU 2009) several areas with pastures and Mediterranean maquis (10.7\%) and artificial pine and Eucalyptus stands (3.7\%). Most of this area consists of cropland $(80.9 \%)$, which mainly includes monocultures of wheat (Triticum spp.) that are only rarely alternated with grassland and other cultivars, such as broad beans (Vicia $f a b a$ ), in a triennial rotational schedule. Like most common crops, artichokes (Cynara spp.) and horticultural crops are alternated biannually. Among woody crops in the area, vineyards are the most common, usually structured in covered stands (Prato and Signorello 2009). Natural vegetation, such as Mediterranean maquis with Rhamnus oleoides, Pistacia lentiscus and small thickets of Quercus ilex and Quercus suber, together with Helichrysum stoechas and Stipa capensis garrigues, and Hyparrhenia hirta grasslands, is present along slopes, in uncultivated land and along fields. The Gela Plain is included (Gariboldi et al. 2000; Brunner et al. 2004) in the Important Bird Area no. 166 and incorporates a Special Protection Area no. ITA050001, and a Site of Community Importance (ITA050011). Our study site was composed of 
(A)

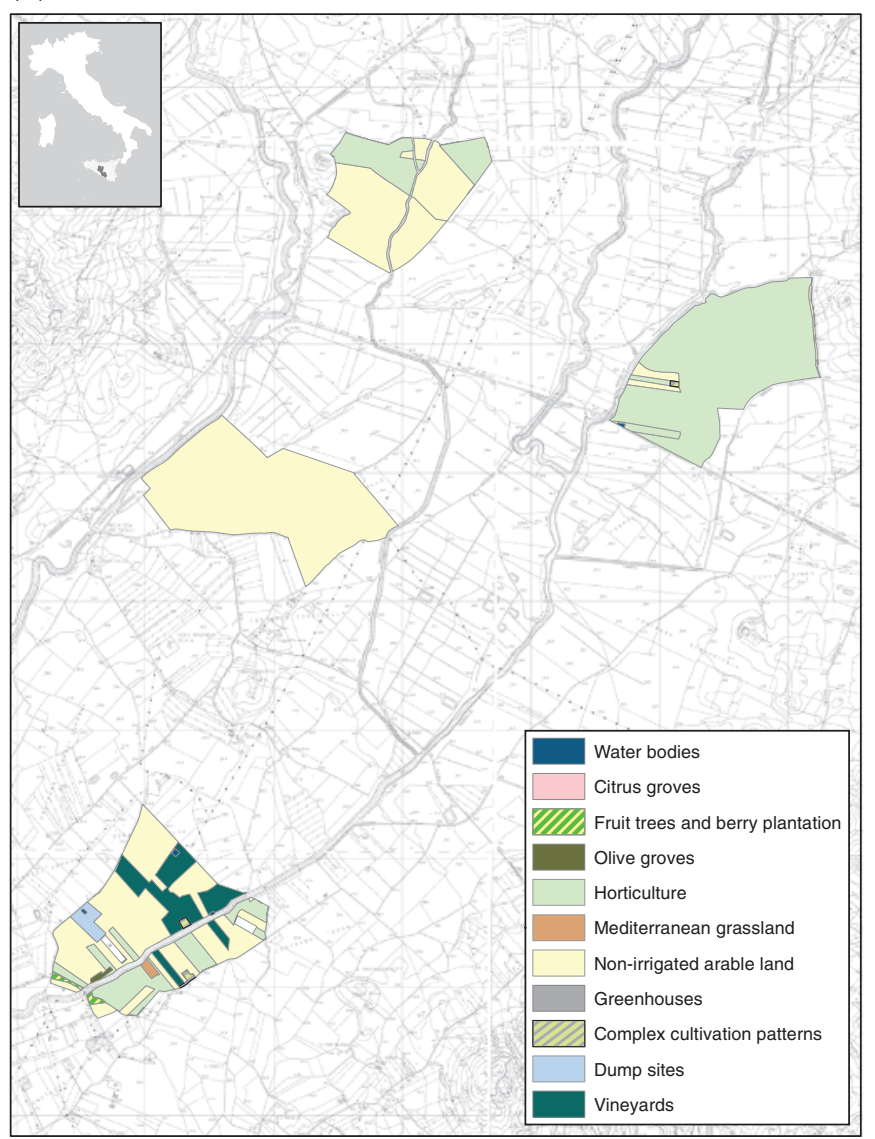

(B)

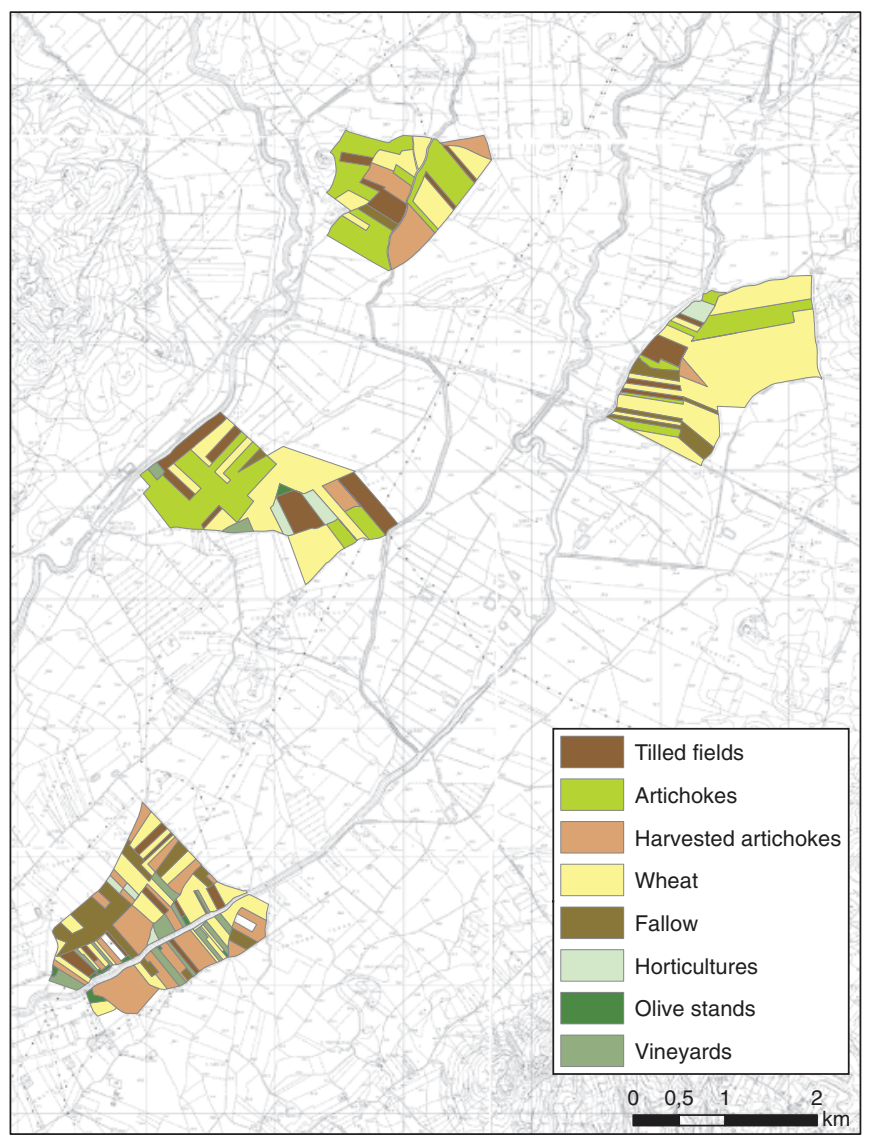

Fig. 1. Land cover classes of the Gela Plain as $(A)$ obtained from the CORINE land cover database (V level) and $(B)$ modified by field surveys conducted in this study. The list order of the land cover classes in $B$ indicates the ordinal increase of the vegetation height classes adopted as one of the environmental predictors for the distribution model of the stone curlew.

four plots (499 ha, Fig. 1) of $125 \pm 21$ ha each (mean \pm s.d.; $\min -\max =91-147 \mathrm{ha}) \sim 2 \mathrm{~km}$ apart from each other. The soil composition of the plots was extremely homogenous, as all of the Gela Plain is classified as eutric fluvisols, which is a type of alluvial deposit composed predominantly of clay (Fierotti et al. 1988). The borders of each plot were drawn following the cultivation edges to reach an approximate extension of $120 \mathrm{ha}$. Plots were randomly chosen among the territories known to be nesting sites of stone curlews (Mascara and Sarà 2007).

\section{Presence data collection}

From May to August 2007 and 2008, the presence of stone curlews was recorded by direct counts of individuals spotted from 23 fixed monitoring stations $(9 \pm 3.27$ per plot) according to the census technique indicated by Bibby et al. (2000). At the end of the spotting time $(3-4 \mathrm{~h})$ in each census session, two or three operators walked together across each study plot along the same transects to flush out hidden birds and to record accurately the field units with tall and dense vegetation (Triolo et al. 2009). Each station was at least $250 \pm 30 \mathrm{~m}$ from the next one to allow for independent counting. This was also allowed by local topography or presence of other obstacles, such as natural vegetation or human settlement, which did not permit stone curlew detection further than $250 \mathrm{~m}$. During spring and summer, stone curlews are very territorial and rarely move into a conspecific's home range, especially during daylight hours (Green et al. 2000; Vaughan and Jennings 2005).

We conducted 144 monitoring sessions in total (four per station), during four monitoring periods (period 1, May; period 2, June; period 3, July; period 4, August), i.e. from egg incubation to juvenile presence. Each plot was surveyed four times with two sessions in the morning (06:00-10:00) and two in the afternoon (17:30-20:30). We recorded the position of every bird observed during the 'spotting time' or at the moment of flushing using a GPS receiver (Garmin ${ }^{\circledR}$ eTrex). The recorded position represented the centre of three circular windows (with radii of 50,100 , and $200 \mathrm{~m}$ ) within which the environmental variables were later recorded. The observations were conducted using $10 \times 40$ magnification binoculars and 20-60 spotting scopes.

We also tried to record the positions of individuals that were heard but not seen; however, we decided not to include these data as presence points because they might exhibit a greater margin of error in exact traceability. 


\section{Ecogeographical predictors}

We considered two types of environmental descriptor classes, habitat and anthropogenic variables, as factors potentially affecting stone curlew distribution. We modelled the study area by entering each variable map as a GIS layer. Each map was then converted into a raster map composed of a grid of 49020 cells of $100 \mathrm{~m}^{2}$ each (ArcMap 9.2, ESRI, Redlands, CA).

We started from GIS databases according to CORINE land cover classes, V level (Fig. 1A, European Environment Agency 2000) and modified them, when necessary, using more detailed classes obtained by surveying the landscape (Fig. 1B). The main goal of this survey was to detail land categories so that they could exactly describe, both spatially and temporally, the real diurnal land use that occurred during the stone curlew breeding season. The choice to assemble our own environmental database was made for two reasons. First, although including a large number of land classes, national cartography may often include very different types of land cover, such as different vegetation cover and height, within large categories. As an example, in our four study plots, the generic class 'non-irrigated arable land' of the CORINE land cover database included wheat, artichokes and harvested artichokes (Fig. 1). Second, this cartography did not account for profound habitat modifications that may occur during the stone curlew breeding season. According to Bossard et al. (2000), the following habitat variables were recorded during field surveys: the types of land use, the edges of each cultivation plot, water bodies, the width of water-fringe vegetation, and the height of vegetation. Among the land uses, we included in the 'fallow' category fallow areas, ex-arable land, and plots that had never been cultivated, because of their similarity in vegetation structure, composition and disturbance. Vegetation height was classified into eight ordinal classes, for which the gradient is shown in the legend order of Fig. $1 B$. Stone curlews are occasionally reported to breed near isolated trees (Vaughan and Jennings 2005). The presence of very few trees on the Gela Plain (on the total 499 ha monitored) prevented us from statistically quantifying tree occurrence as an ecogeographical predictor for stone curlew distribution. However, we did include young olive stands among environmental predictors, but these were excluded by the first step of our model (see Results).

With respect to anthropogenic variables, we located stubble fields fired after tillage, field edges, rural buildings, and service roads that were at most 3-4 m wide. For each type of land use, we developed an index of agricultural impact by summing up the values of the following variables: 1) for sowing, harvesting, ploughing, rotovating, and irrigating, a binomial value was assigned $(0=$ absence, $1=$ presence $) ; 2)$ for organic fertilisation, an increase of one unit for each 50 units of fertilisers was used according to Prato and Signorello (2009). Within each field, we recorded the number of months in which any of the aforementioned agricultural treatments took place, and we denoted this variable as the 'period of field activities'.

Raster maps were converted into Idrisi files and then processed and analysed using Biomapper 4.0 (Hirzel et al. 2007). We used the module CircAn in Biomapper 4.0 to determine the frequency of occurrence of land cover variables within a circular window with a radius of 50,100 , or $200 \mathrm{~m}$ to examine the ecological requirements of breeding stone curlews at different scales of analysis. The DistAn module of Biomapper 4.0 was used to create maps of the distance from the focal cell to a cell with the presence of edges, rural buildings, and roads.

Preliminarily, 16 variables were analysed based on the crossvalidation indices, but only 12 of these were retained for the final model (see Results). It was necessary to normalise the distribution of the 'fallow' variable using the Box-Cox algorithm (Sokal and Rohlf 1994).

\section{Ecological Niche Factor Analysis}

We used Ecological Niche Factor Analysis (Hirzel et al. 2002) to examine the ecological niche (Hutchinson 1957) of stone curlews and to determine a model that best matched their distribution on the Gela Plain. We developed three models at three different spatial scales of analysis with a radius of $50 \mathrm{~m}$ (hereafter $\left.\mathrm{ENFA}_{50}\right), 100 \mathrm{~m}\left(\mathrm{ENFA}_{100}\right)$, or $200 \mathrm{~m}\left(\mathrm{ENFA}_{200}\right)$ from the observation points. Ecological Niche Factor Analysis minimises multicolinearity and redundancy by extracting the relevant ecological information from a set of environmental variables (Hirzel et al. 2002). The results of ENFA describe the environmental niche of a species by using 'marginality' and 'specialisation/tolerance' indices (Hirzel et al. 2002). Within a range of $0-1$, marginality indicates whether the environmental conditions selected by the species are different from the average conditions within the study area (e.g. the closer the index approaches to 1 , the more species condition requirements are marginally represented in the area). Specialisation measures the extent to which distribution of the environmental conditions used by the species is narrow compared with the overall distribution of ecological variables in the study area. As it ranges between 1 and infinity, the specialisation index is better interpreted by using its inverse, the tolerance index (Hirzel et al. 2002). Within a range of $0-1$, the closer the tolerance index approaches to 0 , the more the species is specialised on a narrow range of specific conditions. Marginality and specialisation/ tolerance are uncorrelated factors, and the marginality value is shown as the first factor, while specialisation is contained within the second and subsequent factors extracted through ENFA (Hirzel et al. 2002). Comparison with MacArthur's broken stick distribution (MacArthur 1960; Hirzel et al. 2002) allows the selection of factors to be retained because they explain most of the distribution information.

\section{Habitat suitability maps}

Habitat suitability scores were computed using the harmonic mean algorithm for each pixel of the study area. The harmonic mean best suits cases similar to that of the stone curlew on the Gela Plain, with a relatively low number of presence points that participate with equal weight in the model (Hirzel and Arlettaz 2003). Partial suitability scores were obtained for each factor as the per cent distance to the harmonic mean scores of the observed presence. Overall habitat suitability was then computed as the weighted average of the partial scores according to the variability explained by each factor (Hirzel et al. 2002). Habitat suitability scores vary from 0 , unsuitable habitat, to 100 , the most suitable habitat.

We evaluated the predictive power and the accuracy of the habitat suitability models using the 4-fold cross-validation 
procedure implemented in Biomapper 4.0 (Boyce et al. 2002; Hirzel et al. 2007). The presence dataset was divided into four partitions that were chosen randomly and that did not overlap geographically. Each partition was, in turn, used four times to evaluate the predictions of a model calibrated on the other three partitions (Boyce et al. 2002; Hirzel et al. 2006). To assess the model's accuracy, we used the Boyce index B4 (BI; Boyce et al. 2002), in which high mean values indicate consistency with the evaluation points, and low standard deviations indicate robust predictions. The BI calculates the ratio between the predicted and the expected presence frequencies for each suitability class. We defined three classes of habitat suitability (hereafter referred to as unsuitable, marginal, and suitable) and counted how many presence points of the evaluation partition fell into each class. We classified unsuitable habitat as areas with no presence points, marginal habitat as areas in which the presences were less frequent than expected, and suitable habitat as areas in which the presences were more than expected by chance (Hirzel et al. 2006). In the range -1 to +1 , a BI close to 1 indicates a high predicted power for the model, and thus, the model predictions are well supported by the evaluation data, whereas a value close to 0 indicates a random model (Boyce et al. 2002; Hirzel et al. 2006). We compared the percentages of the study area in the three habitat classes from the different ENFA models by using a test between the proportions $\left(Z_{c} ;\right.$ Zar 1999).

\section{Results}

We recorded a total of 81 stone curlews, 73 of which were adults and 8 juveniles. Among the adults, at least 48 were probably breeding as they were seen as a pair, 12 with juveniles, 30 without juveniles and 6 as part of trios.
For all ENFA models at different spatial scales, a preliminary analysis indicated horticulture areas, olive stands, vineyards, and rivers as land use classes that did not participate in the modelled distribution of the stone curlew.

The best accuracy and predictive power was shown by the ENFA $_{200}$ model, with a mean \pm s.d. Boyce Index of $0.72 \pm 0.39$, followed by $\mathrm{ENFA}_{50}(\mathrm{BI}=0.59 \pm 0.46)$, and, lastly, by $\mathrm{ENFA}_{100}$ $(\mathrm{BI}=0.39 \pm 0.76)$. This last model was discarded for further analyses because the low mean value of the BI indicated a model close to random, and its high s.d. indicated a very poor predictive power.

For the best model, ENFA 200 , MacArthur's broken-stick procedure reduced the 12 predictors into 5 factors that explained $88 \%$ of the total information $(100 \%$ of marginality and $83 \%$ of specialisation; Table 1 ). The global marginality index was 0.7 , indicating that the habitat of the stone curlew differed from the average conditions in the area. The global tolerance index of 0.5 initially indicated a species with a medium-wide environmental niche.

Examination of the marginality and tolerance scores for each habitat variable (Table 1 ) revealed that the stone curlew was found in fields of harvested artichokes and tilled fields much more frequently than expected from the occurrence of these habitat categories in the study site, indicating a preference towards these two land uses. On the contrary, stone curlews strongly avoided tall vegetation (i.e. observation records were much less than expected) and were highly intolerant of this habitat type (i.e. tolerance index close to 0 , Table 1).

Observation of the marginality and tolerance scores for each anthropogenic variable (Table 1) indicated that stone curlew presence was strongly and negatively correlated with recently burnt fields, towards which it also showed high intolerance.

Table 1. Correlation between the $\operatorname{ENFA}_{200}$ factors and the 12 environmental variables concurring for the distribution model of the stone curlew on the Gela Plain (Italy)

The table also shows the contribution of each variable to the global marginality (M) and tolerance $(t=1 /$ specialisation $)$ indices. Factor 1 explains $100 \%$ of the marginality, whereas specialisation is explained by the percentages between brackets shown below each factor

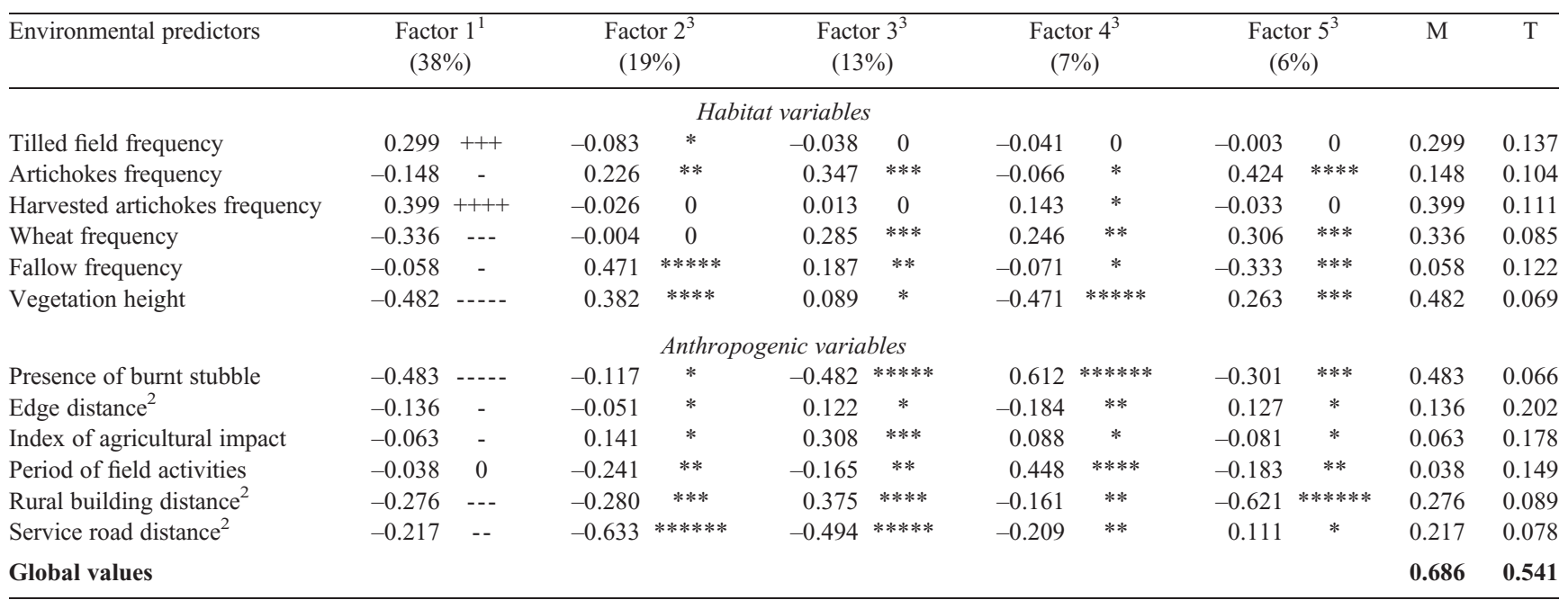

\footnotetext{
${ }^{1}$ Marginality factor: $+/-$ the species locations are positively or negatively correlated with the environmental variable; 0 indicates no correlation between the species distribution and the environmental variable; the higher the number, the higher the correlation.

${ }^{2}$ Avoidance (indicated by a minus sign) of an increasing distance to the variable means a positive correlation (or preference to proximity) to the same variable.

${ }^{3}$ Specialisation factor: the further from 0 , the narrower the range of species conditions than those available; the higher the number of asterisks, the narrower the species niche.
} 
On the contrary, the stone curlew was positively associated with the vicinity of rural buildings and service roads, though with a slightly weaker correlation. Tolerance index scores close to 0 indicated that the stone curlew was characterised by a restricted niche in relation to these last types of human settlements (Table 1).

In comparison with the ENFA 200 , the ENFA 50 qualitatively selected the same variables to explain preferences and avoidances in the distribution of the stone curlew (Tables 1, 2). The habitat suitability map obtained from the ENFA $_{50}$ model showed that the most suitable habitat for the stone curlew represented $5 \%$ of the total study area, and this was reduced to $1 \%$ of the map area in the $\mathrm{ENFA}_{200}$ model (Fig. 2). In comparison with the $\mathrm{ENFA}_{50}$, the $\mathrm{ENFA}_{200}$ model showed a significant decrease of the suitable $\left(Z_{c}=3.77, P=0.0002\right)$ and marginal $\left(Z_{c}=2.25, \quad P=0.0437\right)$ habitat and an increase of the unsuitable area $\left(Z_{c}=3.92, P=0.0003\right.$; Fig. 3).

\section{Discussion}

Our results indicated that the stone curlew was a species with very specific environmental preference and avoidance patterns that preferred marginal habitats, i.e. less represented in terms of their extent compared with the habitats available in the study area. While it was tolerant to a certain degree of variation from its preferred environmental conditions, the stone curlew exhibited a quite narrow niche with respect to the avoided environmental factors. Analysis of the niche breadth was not only an efficient tool that indicated environmental preferences and avoidances but also an essential step in contouring a distribution map of the most suitable habitat for the stone curlew.
With respect to both habitat and anthropogenic preferences, stone curlews were observed more than expected in areas characterised by short vegetation and in the vicinity of rural buildings and service roads. In contrast, stone curlews avoided any fields with tall vegetation, such as wheat fields, and areas that were recently burnt. It is worth noting that neither fallow fields nor agricultural activities were environmental variables that were significantly preferred or avoided by stone curlews.

Our results confirmed that the main characteristic of the ecology of the stone curlew is the avoidance of tall vegetation (Green and Griffiths 1994; Green et al. 2000; Vaughan and Jennings 2005; Delgado et al. 2006). In fact, our niche analysis indicated that stone curlews exhibit the second highest level of intolerance towards tall vegetation and a significant preference toward short vegetation land cover, such as fields that were tilled or, especially, where artichokes were harvested.

On the Gela Plain, artichokes are generally harvested from December until early March, whereas some other artichoke fields are harvested later in April because of a quick change in the market prices. In the first case, at the beginning of their nesting season, stone curlews would find fields with rows of harvested plants reduced to short and dry stems intermingled with bare soil strips (the preferred 'harvested artichokes' in Tables 1, 2). In the second case, stone curlews would find fields of fully leaved artichoke plants (not preferred 'artichokes' in Tables 1,2) with some activities conducted by men on foot, a disturbance to which stone curlews are particularly vulnerable (Taylor 2007). Then, the harvested fields are treated according to two agricultural regimes: one that follows the natural cycle of the plant; the other that forces

Table 2. Correlation between the $\mathbf{E N F A}_{50}$ factors and the 12 environmental variables concurring for the distribution model of the stone curlew on the Gela Plain (Italy)

The table also shows the contribution of each variable to the global marginality $(\mathrm{M})$ and tolerance $(t=1 /$ specialisation) indices. Factor 1 explains $100 \%$ of the marginality, whereas specialisation is explained by the percentages between brackets shown below each factor

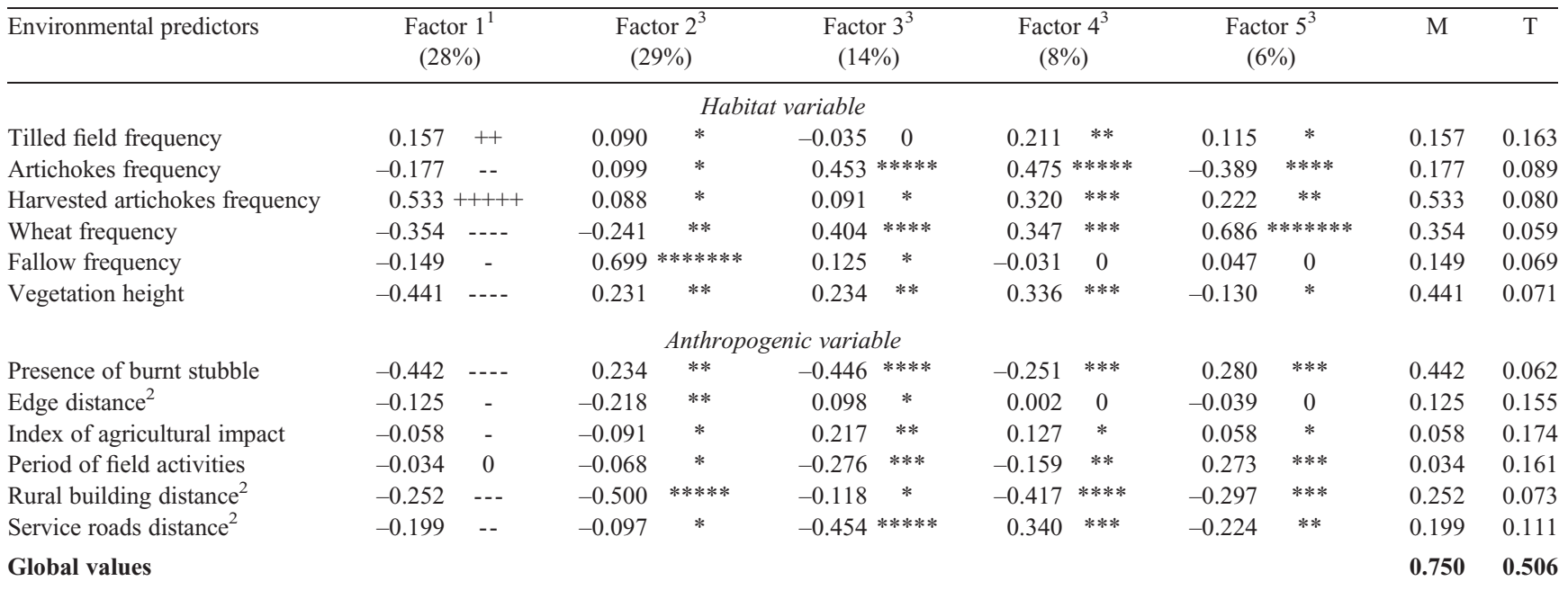

\footnotetext{
${ }^{1}$ Marginality factor: $+/-$ the species locations are positively or negatively correlated with the environmental variable; 0 indicates no correlation between species distribution and the environmental variable; the higher the number of the symbols the higher the correlation.

${ }^{2}$ Avoidance (indicated by a minus sign) of an increasing distance to the variable means a positive correlation (or preference to proximity) to the same variable. ${ }^{3}$ Specialisation factor: the further from 0 , the narrower the range of species conditions than available; the higher the number of asterisks, the narrower the species niche.
} 

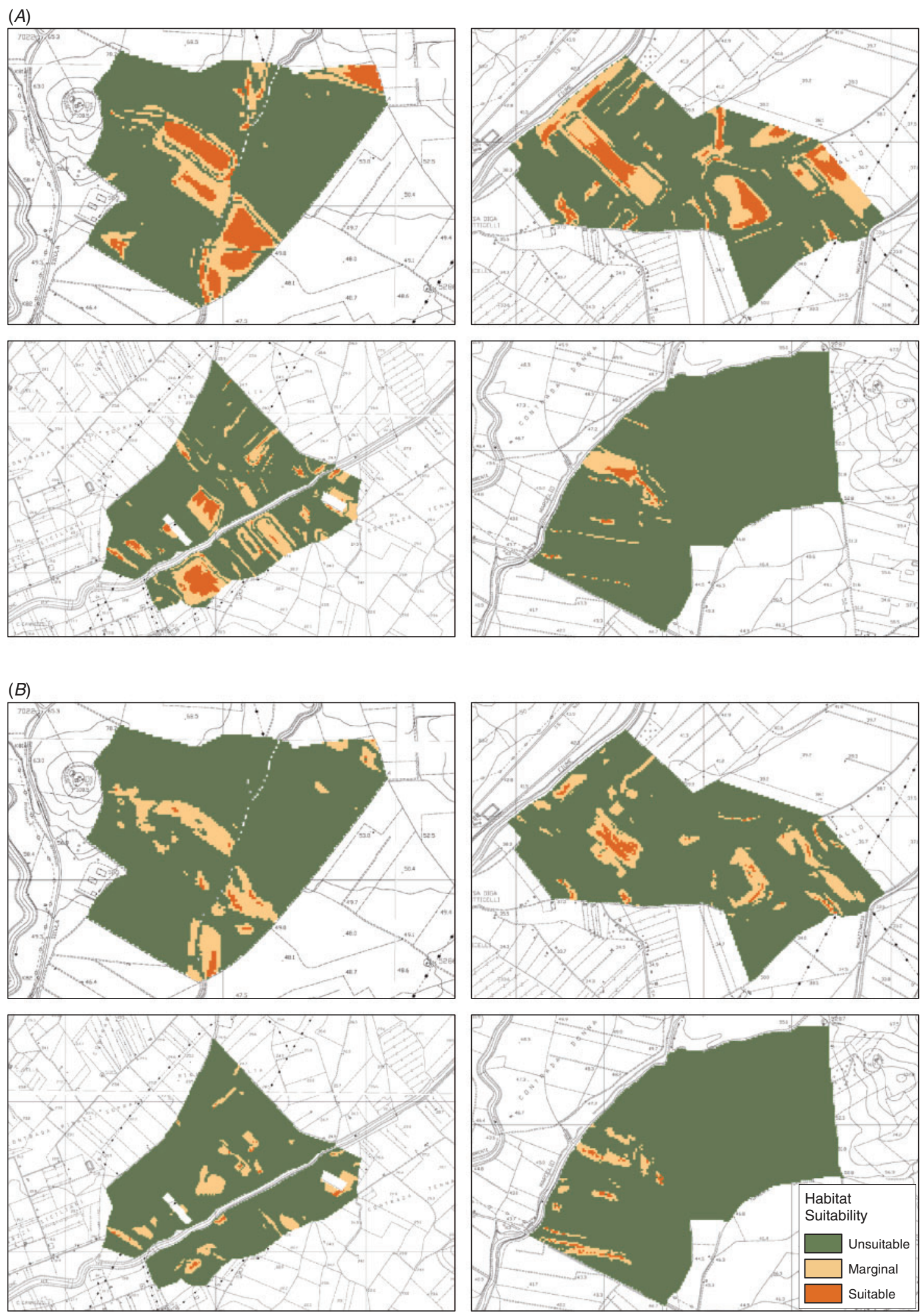

Fig. 2. Habitat suitability maps obtained from ENFA models operating with a radius of $(A) 50 \mathrm{~m}$ or $(B) 200 \mathrm{~m}$ from the observation points of stone curlews on the Gela Plain (Italy). 


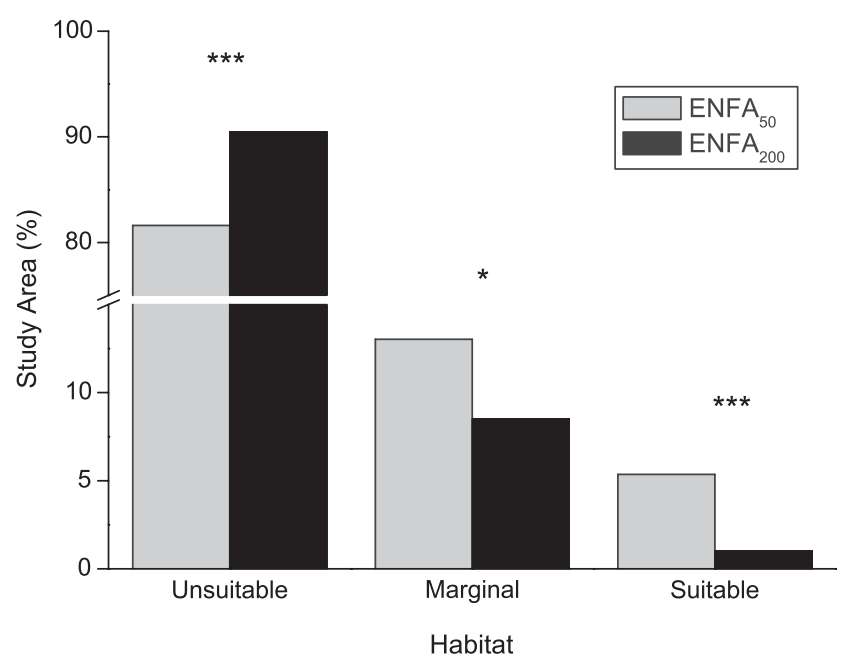

Fig. 3. Percentages of suitable, marginal and unsuitable habitat area resulting from the reclassified maps based on ENFA models operating with a radius of $50 \mathrm{~m}\left(\mathrm{ENFA}_{50}\right)$ or $200 \mathrm{~m}\left(\mathrm{ENFA}_{200}\right)$ from the observation points of stone curlews on the Gela Plain (Italy). Test of difference between proportions $\left(Z_{\mathrm{c}}\right): * P \leq 0.05, * * * P \leq 0.001$.

its growth (Mauromicale et al. 2005). In the first case, harvested fields are left undisturbed until the next autumn, whereas, in the most common case, in late May-July, fields are ploughed and rotovated to prepare the soil for planting a new cycle of production. As a consequence, this last regime may function as a sort of ecological trap, in that it turns optimal breeding habitats into hazardous environments for stone curlew nests.

Among anthropogenic factors, stone curlews showed a positive selection for habitats in proximity to rural buildings, pathways and small service roads, and this preference was a highly specialised one. Distance to roads and buildings has previously been used as a proxy for disturbance events (Donázar et al. 1993; Morán-López et al. 2006). On the Gela Plain, however, the unpaved pathways and service roads are narrow and used by landowners and workers intermittently. They are utilised infrequently by traffic and, therefore, suffer little acoustic or visual disturbance. In addition, our random observations suggested that the borders around human settlements and service roads are the areas least disturbed by agricultural vehicles, particularly during tillage. Further investigations are needed to quantify the disturbance events associated with each of these environmental variables (Taylor 2007). This may better explain the distribution of the stone curlew, and may also elucidate the use of vegetation strips around agricultural plots, buildings and service roads to avoid egg destruction during agricultural activities (Green et al. 2000).

We found that stone curlews were extremely intolerant to disturbances related to fires, such that they were consistently found far from burnt fields. Burning of stubble is employed in Mediterranean areas as a common, although illegal, agricultural practice (Naveh 1990). Wildfires disrupt vertebrate communities (Sarà et al. 2006), increase habitat fragmentation (Deng and Gao 2005), and result in major environmental modifications that seriously affect populations of farmland specialist species (Humple and Holmes 2006).
Stone curlews slightly avoided agricultural activities, towards which they showed only a little tolerance. This result might be a spurious correlation caused by the marked preference of stone curlews for harvested artichoke and tilled fields, areas with rather infrequent or temporary agricultural operations. Our index of agricultural impact also included the fertiliser load used in the area. The observed tolerance of stone curlews to agricultural activities is puzzling considering that stone curlew clutches accumulate chlororganic elements (Nipkow 1989), and pesticide contamination depresses hatching success (Hart et al. 2006). In addition, pesticides and biocides may also decrease the food availability for insectivorous, surface foraging stone curlews (Amat 1986; Groner and Ayal 2001; Ghilain and Bélisle 2008). Future studies could further investigate agricultural impacts on stone curlews by compiling a database of actual activities and soil contamination associated with local cropland.

On the Gela Plain, the population of stone curlews slightly avoided natural vegetation in uncultivated fields, in contrast with other populations that preferred natural habitat, as long as it was kept short by cattle and rabbit grazing (Bealey et al. 1999; Vaughan and Jennings 2005). On the Gela Plain, sheep grazing occurs on temporarily fallow land and in wheat fields after harvest. In the past two decades, the rabbit population has decreased dramatically, and fallow grazing is declining, as it is no longer economically sustainable (LIPU 2009). Some action promoting pasture activity may increase areas with a short sward of natural vegetation and, consequently, increase the optimal habitat available to this curlew population by $7-10 \%$ $\left(\sim 40 \mathrm{~km}^{2}\right)$.

Of the spatial scales employed in our analyses, the largest $(200 \mathrm{~m})$ allowed the depiction of a distribution map of the most suitable habitat for the investigated population based on a robust model with high predictive power (Hirzel et al. 2002). Additionally, the smallest spatial scale investigated was statistically sufficient to highlight the global degree of marginality and specialisation of the stone curlew and provided indications of the individual environmental factors that were most preferred or avoided. However, the model revealed that the small scale (i.e. $50 \mathrm{~m}$ ) had lower predictive power for habitat analysis, and therefore produced less reliable distribution maps on which to locate the most suitable areas for the stone curlew.

Habitat suitability models based on datasets compiled from field surveys allowed us to discriminate a gradient among the nuances of preference and niche breadth exhibited by the stone curlew. Values for environmental variables acquired from national or international sources have the advantage of allowing analyses on a large spatial scale (Haworth and Thompson 1990; Buchanan et al. 2003). With respect to locating potentially suitable habitats, toward which conservation activities may be directed, these sources might become too coarse-grained, and the resulting models might have a decreased explanatory power (Moreno-Rueda and Pizzarro 2009). As our results showed, the high degree of specialisation exhibited by the stone curlew, including a high intolerance towards a few environmental factors, required detailed datasets to discriminate suitable ecological requirements that would have been otherwise obscured by 
using less time-consuming but more coarse-grained cartography sources alone.

Ecological Niche Factor Analysis models contributed to discriminating not only the selected environmental variables, but also the niche breadth, which is a solid parameter for delineating distribution maps. The niche analysis approach successfully employed in the conservation of some specialised species (Basille et al. 2008; Qi et al. 2009) may thus also have vital management implications for the stone curlew. The stone curlew is a species that faces serious conservation issues in all of its distribution range (Pain et al. 1997; Evans and Green 2007; Taylor et al. 2007), as do most avifauna of European steppelike habitats (Brotons et al. 2004; Bota et al. 2005). Our niche analysis detected environmental factors that are important predictors of stone curlew distribution and, therefore, indicated concrete land management actions, such as the prevention of human-induced fire, maintaining natural and short vegetation by increasing pastoral activities, and promoting natural cycles of artichoke cultivation. Our results also showed that stone curlews prefer artichoke fields but this preference needs to be monitored to assess the presence of ecological traps. As stone curlews have also crepuscular and nocturnal habits (Green et al. 2000), an important contribution for setting further concrete management actions would be to integrate our results with habitat preferences, niche breath and distribution maps based on the nocturnal habits of this species.

Our large-scale analysis of databases customised on local territories unravelled species-specific environmental requirements. The application of ENFA to habitat preferences of other steppe species may promote a better understanding of management strategies for preserving European steppe ecosystems (Bota et al. 2005). Furthermore, it may provide insights into which European agricultural policies could be adapted to significantly reduce the rate of biodiversity loss (European Commission 2006).

\section{Acknowledgements}

We thank Emilio Giudice for providing field accommodation and Rosario Mascara for valuable information on the local stone curlew population. Funding was provided by the ex- $60 \%$ grant University of Palermo for the years 2003, 2004 and 2007.

\section{References}

Acevedo, P., Alzaga, V., Cassinello, J., and Gortázar, C. (2007). Habitat suitability modelling reveals a strong niche overlap between two poorly known species, the broom hare and the Pyrenean grey partridge, in the north of Spain. Acta Oecologica 31, 174-184. doi:10.1016/j.actao.2006. 09.003

Amat, J. A. (1986). Information on the diet of the stone curlew Burhinus oedicnemus in Doñana, southern Spain. Bird Study 33, 71-73. doi: $10.1080 / 00063658609476898$

Arroyo, B., García, J. T., and Bretagnolle, V. (2002). Conservation of the Montagu's harrier (Circus pygargus) in agricultural areas. Animal Conservation 5, 283-290. doi:10.1017/S1367943002004031

Basille, M., Calenge, C., Marboutin, E., Andersen, R., and Gaillard, J.-M. (2008). Assessing habitat selection using multivariate statistics: some refinements of the ecological-niche factor analysis. Ecological Modelling 211, 233-240. doi:10.1016/j.ecolmodel.2007.09.006
Bealey, C. E., Green, R. E., Robson, R., Taylor, C. R., and Winspear, R. (1999). Factors affecting the numbers and breeding success of stone curlews Burhinus oedicnemus at Porton Down, Wiltshire. Bird Study 46, 145-156. doi:10.1080/00063659909461126

Benton, T. G., Bryant, D. M., Cole, L., and Crick, H. Q. P. (2002). Linking agricultural practice to insect and bird populations. Journal of Applied Ecology 39, 673-687. doi:10.1046/j.1365-2664.2002. 00745.x

Bibby, C. J., Burgess, N. D., Hill, D. A., and Mustoe, S. H. (2000). 'Bird Census Techniques.' 2nd edn. (Academic Press: London.)

BirdLife International (2004). 'Birds in Europe: Population Estimates, Trends and Conservation Status.' (BirdLife International: Cambridge, UK.)

Bossard, M., Feranec, J., and Otahel, J. (2000). 'CORINE Land Cover Technical Guide. Addendum 2000.' (European Environment Agency: Copenhagen.)

Bota, G., and Morales, M. B., Mañosa, S., and Camprodon, J. (2005). 'Ecology and Conservation of Steppe-land Birds.' (Lynx Edicions \& Tecnològic Forestal de Catalunya: Barcelona, Spain.)

Boyce, M. S., Vernier, P. R., Nielsen, S. E., and Schmiegelow, F. K. A. (2002). Evaluating resource selection functions. Ecological Modelling 157, 281-300. doi:10.1016/S0304-3800(02)00200-4

Braunisch, V., Bollmann, K., Graf, R. F., and Hirzel, A. H. (2008). Living on the edge - modelling habitat suitability for species at the edge of their fundamental niche. Ecological Modelling 214, 153-167. doi:10.1016/j. ecolmodel.2008.02.001

Brichetti, P., and Fracasso, G. (2004). 'Ornitologia italiana. 2: TetraonidaeScolopacidae.' (Alberto Perdisa Editore: Bologna.)

Bro, E., Mayot, P., Corda, E., and Reitz, F. (2004). Impact of habitat management on grey partridge populations: assessing wildlife cover using a multisite BACI experiment. Journal of Applied Ecology 41, 846-857. doi:10.1111/j.0021-8901.2004.00939.x

Brotons, L., Mañosa, S., and Estrada, J. (2004). Modelling the effect of irrigation schemes on the distribution of steppe birds in Mediterranean farmland. Biodiversity and Conservation 13, 1039-1058. doi:10.1023/ B:BIOC.0000014468.71368.35

Brunner, A., Celada, C., Rossi, P., and Gustin, M. (2004). Sviluppo di un sistema nazionale delle ZPS sulla base della rete delle IBA (Important Bird Areas). Available at http://www.lipu.it/IBA [verified March 2011].

Buchanan, G. M., Pearce-Higgings, J. W., Watton, S. R., Grant, M. C., and Whitfield, D. P. (2003). Correlates of the change in the ring ouzel Turdus torquatus abundance in Scotland from 1988-91 to 1999. Bird Study 50, 97-105. doi:10.1080/00063650309461300

Bulgarini, F., Calvario, E., Fraticelli, F., Petretti, F., and Sarrocco, S. (1998). 'Libro Rosso Degli Animali d'Italia, Vertebrati.' (WWF Italy: Rome.)

Burfield, I. J. (2005). The conservation status of steppic birds in Europe. In 'Ecology and Conservation of Steppe-land Birds.' (Eds G. Bota, M. B. Morales, S. Mañosa and J. Camprodon.) pp. 119-140. (Lynx Editions: Barcelona.)

Cramp, S., and Simmons, K. E. L. (1983). 'Handbook of the Birds of the Western Palearctic. Vol. III, From Waders to Gulls.' (Oxford University Press: Oxford, UK.)

Delgado, M. P., Jiménez, D., Carriles, E., García de la Morena, E. L., Morales, M. B., and Traba, J. (2006). Finding a home: density estimates and macroand micro-habitat selection in the Eurasian stone curlew at two localities in central Spain. Journal fur Ornithologie 147, 155-155.

Deng, W. H., and Gao, W. (2005). Edge effects on nesting success of cavity-nesting birds in fragmented forests. Biological Conservation 126, 363-370. doi:10.1016/j.biocon.2005.06.013

Donald, P. F., Green, R. E., and Heath, M. F. (2001). Agricultural intensification and the collapse of Europe's farmland bird populations. Proceedings. Biological Sciences 268, 25-29. doi:10.1098/rspb.2000. 1325 
Donald, P. F., Sanderson, F. J., Burfield, J. I., and van Bommel, F. P. J. (2006). Further evidence of continent-wide impacts of agricultural intensification on European farmland birds, 1990-2000. Agriculture Ecosystems \& Environment 116, 189-196. doi:10.1016/j.agee.2006.02.007

Donald, P. F., Sanderson, F. J., Burfield, I. J., Bierman, S. M., Gregory, R. D., and Waliczky, Z. (2007). International conservation policy delivers benefits for birds in Europe. Science 317, 810-813. doi:10.1126/ science. 1146002

Donázar, J. A., Hiraldo, F., and Bustamante, J. (1993). Factors influencing nest site selection, breeding density and breeding success in the bearded vulture Gypaetus barbatus. Journal of Applied Ecology 30, 504-514. doi: $10.2307 / 2404190$

European Commission (Ed.) (2006). Halting the Loss of Biodiversity by 2010 - and Beyond. Sustaining Ecosystem Services for Human Wellbeing. Available at: http://ec.europa.eu/environment/ [verified March 2011].

European Environment Agency (2000). Corine Land Cover Technical guide. Addendum 2000. Available at: http://www.eea.eu.int [verified March 2011].

Evans, A. D., and Green, R. E. (2007). An example of a two-tiered agrienvironment scheme designed to deliver effectively the ecological requirements of both localized and widespread bird species in England. Journal fur Ornithologie 148, 279-286. doi:10.1007/s10336-0070216-3

Falcucci, A., Ciucci, P., Maiorano, L., Gentile, L., and Boitani, L. (2009). Assessing habitat quality for conservation using an integrated occurrence-mortality model. Journal of Applied Ecology 46, 600-609. doi:10.1111/j.1365-2664.2009.01634.x

Fierotti, G., Dazzi, C., and Raimondi, S. (1988). 'Carta dei Suoli della Sicilia in scala $1: 250.000$.' (Regione Siciliana - Assessorato Territorio ed Ambiente: Palermo.)

Gariboldi, A., Rizzi, V., and Casale, F. (2000). 'Aree Importanti per l'Avifauna in Italia.' (LIPU: Italy, Parma.)

Ghilain, A., and Bélisle, M. (2008). Breeding success of the swallows along a gradient of agricultural intensification. Ecological Applications 18, 1140-1154. doi:10.1890/07-1107.1

Gomes, L., Grilo, C., Silva, C., and Mira, A. (2009). Identification methods and deterministic factors of owl roadkill hotspot locations in Mediterranean landscapes. Ecological Research 24, 355-370. doi:10.1007/s11284-008-0515-z

Goriup, P. D. (Ed.) (1988). The avifauna and conservation of steppic habitats in western Europe, north Africa and the Middle East. In 'Ecology and Conservation of Grassland Birds'. pp. 145-158. (ICBP/ BirdLife Technical Publication Series 7: Cambridge, UK)

Green, R. E., and Griffiths, G. H. (1994). Use of preferred nesting habitat by stone curlews Burhinus oedicnemus in relation to vegetation structure. Journal of Zoology 233, 457-471. doi:10.1111/j.1469-7998.1994. tb05277.x

Green, R. E., Tyler, G. A., and Bowden, C. G. R. (2000). Habitat selection, ranging behaviour and diet of the stone curlew (Burhinus oedicnemus) in southern England. Journal of Zoology 250, 161-183. doi:10.1111/ j.1469-7998.2000.tb01067.x

Gregory, R. D., Wilkinson, N. I., Noble, D. G., Robinson, J. A., Brown, A. F., Hughes, J., Procter, D. A., Gibbons, D. W., and Galbraith, C. A. (2002). The population status of birds in the United Kingdom, Channel Islands and Isle of Man: an analysis of conservation concern 2002-2007. British Birds 95, 410-450.

Groner, E., and Ayal, Y. (2001). The interaction between bird predation and plant cover in determining habitat occupancy of darkling beetles. Oikos 93, 22-31. doi:10.1034/j.1600-0706.2001.930102.x

Guisan, A., and Zimmermann, K. (2000). Predictive habitat distribution models in ecology. Ecological Modelling 135, 147-186. doi:10.1016/ S0304-3800(00)00354-9
Hart, J. D., Milsom, T. P., Fisher, G., Wilkins, V., Moreby, S. J., Murray, A. W. A., and Robertson, P. A. (2006). The relationship between yellowhammer breeding performance, arthropod abundance and insecticide applications on arable farmland. Journal of Applied Ecology 43, 81-91. doi:10.1111/j.1365-2664.2005.01103.x

Haworth, P. F., and Thompson, D. B. A. (1990). Factors associated with the breeding distribution of upland birds in the south Pennines, England. Journal of Applied Ecology 27, 562-577. doi:10.2307/2404302

Herkert, J. R. (1997). Bobolink Dolichonyx oryzivorus population decline in agricultural landscapes in the midwestern USA. Biological Conservation 80, 107-112. doi:10.1016/S0006-3207(96)00066-3

Hirzel, A. H., and Arlettaz, R. (2003). Modelling habitat suitability for complex species distributions by the environmental-distance geometric mean. Environmental Management 32, 614-623. doi:10.1007/s00267003-0040-3

Hirzel, A. H., Helfer, V., and Metral, F. (2001). Assessing habitat suitability models with a virtual species. Ecological Modelling 145, 111-121. doi:10.1016/S0304-3800(01)00396-9

Hirzel, A. H., Hausser, J., Chessel, D., and Perrin, N. (2002). Ecologicalniche factor analysis: how to compute habitat suitability maps without absence data? Ecology 83, 2027-2036. doi:10.1890/0012-9658(2002) 083[2027:ENFAHT]2.0.CO;2

Hirzel, A. H., Posse, B., Oggier, P. A., Crettenand, Y., Glenz, C., and Arlettaz, R. (2004). Ecological requirements of reintroduced species and the implications for release policy: the case of the bearded vulture. Journal of Applied Ecology 41, 1103-1116. doi:10.1111/j.0021-8901. 2004.00980.x

Hirzel, A. H., Le Lay, G., Helfer, V., Randin, C., and Guisan, A. (2006). Evaluating the ability of habitat suitability models to predict species presences. Ecological Modelling 199, 142-152. doi:10.1016/j.ecolmodel. 2006.05.017

Hirzel, A. H., Hausser, J., and Perrin, N. (2007). 'Biomapper 1.0-4.0.' (University of Lausanne: Switzerland.)

Humple, D. L., and Holmes, A. L. (2006). Effects of fire on a breeding population of loggerhead shrikes in sagebrush steppe habitat. Journal of Field Ornithology 77, 21-28. doi:10.1111/j.1557-9263. 2006.00004.x

Hutchinson, G. E. (1957). Concluding remarks. In 'Cold Spring Harbour Symposium on Quantitative Biology, Vol. 22'. pp. 415-427.

Ientile, R., and Massa, B. (2008). Uccelli (Aves). In 'Atlante della Biodiversità della Sicilia: Vertebrati terrestri. Studi e Ricerche'. Vol. 6. (Arpa Sicilia: Palermo.)

LIPU (2009). Piano di Gestione Siti di Importanza Comunitaria 'Biviere Macconi di Gela'. (Rete Natura 2000 - POR Sicilia 2000-2006.)

MacArthur, R. H. (1960). On the relative abundance of species. American Naturalist 94, 25-36. doi:10.1086/282106

Mascara, R., and Sarà, M. (2007). Censimento di specie d'uccelli steppicocerealicole d'interesse comunitario nella Piana Di Gela (Sicilia sudorientale). Naturalista Siciliano 31, 27-39.

Mauromicale, G., Ierna, A., and Licandro, P. (2005). Harvest time and yield of globe artichoke in relation to the production environment of plantlets. Proceedings of the fourth international congress on artichoke Acta Horticulturae 681, 117-125.

Morán-López, R., Sanchez Guzman, J. M., Costillo Borrego, E., and Villegas Sanchez, A. (2006). Nest-site selection of endangered cinereous vulture Aegypius monachus populations affected by anthropogenic disturbance: present and future conservation implications. Animal Conservation 9, 29-37. doi:10.1111/j.1469-1795. 2005.00003.x

Moreno-Rueda, G., and Pizzarro, M. (2009). Relative influence of habitat heterogeneity, climate, human disturbance, and spatial structure on vertebrate species richness in Spain. Ecological Research 24, 335-344. doi:10.1007/s11284-008-0509-x 
Naveh, Z. (1990). Fire in the Mediterranean, a landscape ecological perspective. In 'Fire Ecosystem Dynamics'. (Eds J. G. Goldammer and M. J. Jenkins.) pp. 1-20. (Academic Publishing: Den Haag, The Netherlands.)

Nipkow, M. (1989). Rückstände chlororganischer Verbindungen in Gelegen des Triels (Burhinus oedicnemus) im Elsaß. Journal fur Ornithologie 130, 79-82. doi:10.1007/BF01647165

Onrubia, A., and Andrès, T. (2005). Impact of human activities on steppicland birds: a review in the context of the western palearctic. In 'Ecology and Conservation of Steppe-land Birds'. (Eds G. Bota, M. B. Morales, S. Mañosa and J. Camprodon.). pp. 185-211. (Lynx Edicions: Barcelona.)

Pain, D. J., Hill, D., and McCracken, D. I. (1997). Impact of agricultural intensification of pastoral systems on bird distributions in Britain 1970-1990. Agriculture Ecosystems \& Environment 64, 19-32. doi:10.1016/S0167-8809(96)01126-7

Pépin, D., Birkan, M., and Angibault, J.-M. (2008). Factors affecting changes in grey partridge population dynamics in a French arable farmland over an eleven-year period. European Journal of Wildlife Research 54, 179-187. doi:10.1007/s10344-007-0125-z

Prato, C., and Signorello, G. (2009). Relazione agronomica. In 'Piano di Gestione Siti di Importanza Comunitaria "Biviere Macconi di Gela" , pp. 567-787. (Rete Natura 2000 - POR Sicilia 2000-2006.)

Puddu, G., Maiorano, L., Falcucci, A., Corsi, F., and Boitani, L. (2009). Spatial-explicit assessment of current and future conservation options for the endangered Corsican red deer (Cervus elaphus corsicanus) in Sardinia. Biodiversity and Conservation 18, 2001-2016. doi:10.1007/ s10531-008-9569-Z

Qi, D., Hu, Y., Gu, X., Li, M., and Wei, F. (2009). Ecological niche modelling of the sympatric giant and red pandas on a mountain-range scale. Biodiversity and Conservation 18, 2127-2141. doi:10.1007/s10531009-9577-7

Raimondo, F. M. (1998). Carta del paesaggio e della biodiversità vegetale della provincia di Palermo. Quaderni di Botanica Ambientale e Applicata 9, 3-160.

Reif, J., Voříšek, P., Štastný, K., Bejček, V., and Petr, J. (2008). Agricultural intensification and farmland birds: new insights from a central European country. The Ibis 150, 596-605. doi:10.1111/j.1474-919X.2008.00829.x

Ribeiro, R., Santos, X., Silleroc, N., Carreterob, M. A., and Llorentea, G. A. (2009). Biodiversity and land uses at a regional scale: is agriculture the biggest threat for reptile assemblages? Acta Oecologica 35, 327-334. doi:10.1016/j.actao.2008.12.003

Salamolard, M., and Moreau, C. (1999). Habitat selection by little bustard Tetrax tetrax in a cultivated area of France. Bird Study 46, 25-33. doi:10.1080/00063659909461112

Sanderson, F. J., Donald, P. F., and Burfield, I. J. (2005). Farmland birds in Europe: from policy change to population decline and back again. In 'Ecology and Conservation of Steppe-Land Birds'. (Eds G. Bota, M. B. Morales, S. Mañosa and J. Camprodon.) pp. 211-236. (Lynx Edicions \& Centre Tecnòlogic Forestal de Catalunya: Barcelona.)

Santos, X., Brito, J. C., Sillero, N., Pleguezuelos, J. M., Llorente, G. A., Fahd, S., and Parellada, X. (2006). Inferring habitat-suitability areas with modelling techniques and GIS: a contribution to assess the conservation status of Vipera latastei. Biological Conservation 130, 416-425. doi:10.1016/j.biocon.2006.01.003
Sarà, M., Bellia, E., and Milazzo, A. (2006). Fire disturbance disrupts cooccurrence patterns of terrestrial vertebrates in Mediterranean woodlands. Journal of Biogeography 33, 843-852. doi:10.1111/j.1365-2699.2006. 01429.x

Sattler, T., Bontadina, F., Hirzel, A. H., and Arlettaz, R. (2007). Ecological niche modelling of two cryptic bat species for a reassessment of their conservation status. Journal of Applied Ecology 44, 1188-1199. doi:10.1111/j.1365-2664.2007.01328.x

Sim, I. M. W., Burfield, I. J., Grant, M. C, Perce-Higgings, J. W., and Brooke, M. de L. (2007). The role of habitat composition in determining breeding site occupancy in a declining ring ouzel Turdus torquatus population. The Ibis 149, 374-385. doi:10.1111/j.1474-919X.2007.00655.X

Sirami, C., Brotons, L., Burfield, I., Fonderflick, J., and Martin, J. L. (2008). Is land abandonment having an impact on biodiversity? A meta-analytical approach to bird distribution changes in the north-western Mediterranean. Biological Conservation 141, 450-459. doi:10.1016/j.biocon.2007. 10.015

Sokal, R. R., and Rohlf, F. J. (1995). 'Biometry: the Principles and Practice of Statistics in Biological Research.' 3rd edn. (W. H. Freeman \& Company: New York.)

Taylor, E. C. (2007). Stone Curlew Burhinus Oedicnemus and human disturbance: effects on behaviour, distribution and breeding success. Ph.D. Dissertation, University of Cambridge, UK. 286 pp.

Taylor, E. C., Green, R. E., and Perrins, J. (2007). Stone-curlews Burhinus oedicnemus and recreational disturbance: developing a management tool for access. The Ibis 149, 37-44. doi:10.1111/j.1474-919X.2007. 00645.x

Tittensor, D. P., Baco-Taylor, A. R., Brewin, P., Clark, M. R., Consalvey, M., Hall-Spencer, J., Rowden, A. A., Schlacher, T., Stocks, K., and Rogers, A. D. (2009). Predicting global habitat suitability for stony corals on seamounts. Journal of Biogeography 36, 1111-1128. doi:10.1111/ j.1365-2699.2008.02062.x

Triolo, S., Campobello, D., and Sarà, M. (2009). Modello di distribuzione e di idoneità ambientale dell'occhione, Burhinus oedicnemus. In 'Proceedings XV Convegno Italiano Ornitologia'. Sabaudia, Italy. p. 96.

Tucker, G. M., and Heath, M. F. (1994). Birds in Europe their conservation status. Conservation Series 3. (BirdLife International: Cambridge.)

Vaughan, R., and Jennings, N. (2005). 'The Stone Curlew.' (Isabelline Books: Falmouth, UK.)

Wolff, A. (2005). Influence of landscape and habitat heterogeneity on the distribution of steppe-land birds in the Crau, southern France. In 'Ecology and Conservation of Steppe-Land Birds'. (Eds G. Bota, M. B. Morales, S. Mañosa and J. Camprodon.) pp. 141-168. (Lynx Edicions \& Tecnòlogic Forestal de Catalunya: Barcelona.)

Wolff, A., Dieuleveut, T., Martin, J.-L., and Bretagnolle, V. (2002). Landscape context and little bustard abundance in a fragmented steppe: implications for reserve management in mosaic landscapes. Biological Conservation 107, 211-220. doi:10.1016/S0006-3207(02) 00087-3

Zar, J. H. (1999). 'Biostatistical Analysis.' 4th edn. (Prentice Hall: Upper Saddle River, NJ.)

Manuscript received 10 October 2010, accepted 18 February 2011 